\title{
Identification of metastatic nodal disease in a phase 1 dose-escalation trial of intraoperative sentinel lymph node mapping in non-small cell lung cancer using near-infrared imaging
}

\author{
Denis M. Gilmore, MD, ${ }^{\mathrm{a}, \mathrm{b}}$ Onkar V. Khullar, MD, ${ }^{\mathrm{a}, \mathrm{b}}$ Michael T. Jaklitsch, MD, ${ }^{\mathrm{a}}$ Lucian R. Chirieac, MD, ${ }^{\mathrm{c}}$ \\ John V. Frangioni, MD, $\mathrm{PhD},{ }^{\mathrm{d}}$ and Yolonda L. Colson, $\mathrm{MD}, \mathrm{PhD}^{\mathrm{a}}$
}

\begin{abstract}
Objectives: Early-stage non-small cell lung cancer (NSCLC) has a high recurrence rate and poor 5-year survival, particularly if lymph nodes are involved. Our objective was to perform a dose-escalation study to assess safety and feasibility of intraoperative near-infrared (NIR) fluorescence imaging to identify the first tumordraining lymph nodes (ie, sentinel lymph nodes [SLNs] in patients with NSCLC).
\end{abstract}

\begin{abstract}
Methods: A-dose escalation phase 1 clinical trial assessing real-time NIR imaging after peritumoral injection of 3.8 to $2500 \mu \mathrm{g}$ indocyanine green (ICG) was initiated in patients with suspected stage I/II NSCLC. Visualization of lymphatic migration, SLN identification, and adverse events were recorded.
\end{abstract}

\begin{abstract}
Results: Thirty-eight patients underwent ICG injection and NIR imaging via thoracotomy $(\mathrm{n}=18)$ or thoracoscopic imaging $(\mathrm{n}=20)$. SLN identification increased with ICG dose, with fewer than $25 \%$ SLNs detected in dose cohorts of $600 \mu \mathrm{g}$ or less versus $89 \%$ success at $1000 \mu \mathrm{g}$ or greater. Twenty-six NIR ${ }^{+}$SLNs were identified in 15 patients, with $7 \mathrm{NIR}^{+}$SLNs (6 patients) harboring metastatic disease on histologic analysis. Metastatic nodal disease was never identified in patients with a histologically negative $\mathrm{NIR}^{+}$SLN. No adverse reactions were noted.
\end{abstract}

Conclusions: NIR-guided SLN identification with ICG was safe and feasible in this initial dose-escalation trial. ICG doses greater than $1000 \mu$ g yielded nearly 90\% intrathoracic SLN visualization, with the presence or absence of metastatic disease in the SLN directly correlating with final nodal status of the lymphadenectomy specimen. Further studies are needed to optimize imaging parameters and confirm sensitivity and specificity of SLN mapping in NSCLC using this promising imaging technique. (J Thorac Cardiovasc Surg 2013;146:562-70)

\footnotetext{
From the Division of Thoracic Surgery ${ }^{\mathrm{a}}$ and the Department of Pathology, ${ }^{\mathrm{c}}$ Brigham and Women's Hospital, and the Department of Surgery ${ }^{\mathrm{b}}$ and the Division of Hematology/Oncology and the Department of Radiology, ${ }^{\mathrm{d}}$ Beth Israel Deaconess Medical Center, Boston, Mass.

Supported by grant RO1-CA-131044-01A1 from the National Institutes of Health.

Disclosures: Initial patients in this study were imaged using an open platform FLARE near-infrared (NIR) imaging system owned by Beth Israel Deaconess Medical Center. This technology has been licensed to the FLARE Foundation, a non-profit organization focused on promoting the dissemination of medical imaging technology for research and clinical use. Dr Frangioni is the founder and chairman of this foundation, and Beth Israel Deaconess Medical Center and will receive royalties if this technology is sold. Dr Frangioni has elected to surrender postmarket royalties to which he would otherwise be entitled as inventor, and has elected to donate premarket proceeds to the FLARE Foundation. Subsequent patients were imaged using a thoracoscopic NIR imaging system that is on loan to Brigham and Women's Hospital from Novadaq Technologies, without restrictions on study design, patient enrollment, data analysis, or publication. No compensation for research or consultation has been paid, and no author has any conflicts of interest with this company or other conflicts to declare.

Read at the 92nd Annual Meeting of The American Association for Thoracic Surgery, San Francisco, California, April 28-May 2, 2012.

Received for publication July 24, 2012; revisions received April 1, 2013; accepted for publication April 18, 2013; available ahead of print June 21, 2013.

Address for reprints: Yolonda L. Colson, MD, PhD, Department of Thoracic Surgery, Brigham and Women's Hospital, 75 Francis St, Boston, MA 02115 (E-mail: ycolson@ partners.org).

$0022-5223 / \$ 36.00$

Copyright (c) 2013 by The American Association for Thoracic Surgery

http://dx.doi.org/10.1016/j.jtcvs.2013.04.010
}

Regional lymph node status is the most important prognostic indicator in early-stage non-small cell lung cancer (NSCLC). Although noninvasive preoperative staging using computed tomographic (CT) and positron emission tomographic (PET) scans is useful in determining metastatic disease in nodes greater than $1 \mathrm{~cm}$, these modalities frequently miss regional lymphatic metastasis. ${ }^{1}$ Surgical resection and lymphadenectomy remain the standard, but routine complete lymphadenectomy is reported in only $50 \%$ of patients. ${ }^{2-4}$ Furthermore, the practice of lymph node sampling can miss metastatic disease secondary to the propensity of NSCLC to "skip" to N2 mediastinal nodes and the lack of in-depth histologic analysis on multiple sampled nodes. Unfortunately, patients with missed metastatic disease are deemed to have stage I disease and do not receive adjuvant therapy, which likely contributes to the nearly $40 \%$ incidence of recurrent disease and the $50 \%$ to $60 \% 5$-year survival rate reported for patients initially identified with early-stage disease. ${ }^{5-8}$

Compared with other early-stage solid tumors, high recurrence rates and poor overall survival in early-stage NSCLC suggest that patients are understaged and/or undertreated. Poor outcomes may be attributed to inadequate nodal sampling, skip metastases, and/or inadequate 

Abbreviations and Acronyms
$\mathrm{CT}=$ computed tomography
FFP $=$ fresh-frozen plasma
$\mathrm{H} \& \mathrm{E}=$ hematoxylin and eosin
HSA human serum albumin
ICG = indocyanine green
$\mathrm{NIR}=$ near infrared
NSCLC $=$ non-small cell lung cancer
PET $=$ positron emission tomographic
SLN = sentinel lymph node

histologic processing for identification of occult metastases. ${ }^{5-7}$ Sentinel lymph node (SLN) mapping offers the benefit of identifying nodes at greatest risk for metastatic spread, focusing in-depth immunohistochemical analysis on "high-risk" nodes and decreasing morbidity by localizing nodal dissection, and has become the standard of care in breast cancer and melanoma. ${ }^{9,10}$ However, SLN mapping has been unreliable in NSCLC because of difficult anatomic access to hilar structures and a poor signal-to-noise ratio, making tracer visualization in anthractic nodes or identification of radioactive nodes suboptimal. ${ }^{11-16}$ Near-infrared (NIR) imaging has successfully been used for real-time intraoperative SLN identification in cancers of the skin, breast, and gastrointestinal tract ${ }^{17-20}$ and is ideal for in vivo intraoperative imaging because of low absorption, scatter, and tissue autofluorescence within the NIR spectrum $(700-1000 \mathrm{~nm}){ }^{21}$ As a result, NIRfluorescent lymphatic tracers permit surgical dissection without distortion of critical anatomy. ${ }^{22}$ In addition, safety is increased because laser and radioactivity are not required. Indocyanine green (ICG) is a common Food and Drug Administration-approved intravascular dye that also functions as an NIR lymphatic fluorophore. Therefore, we hypothesized that NIR lymphatic imaging with ICG may permit SLN identification in patients with early-stage NSCLC. This article reports results from the first phase 1 doseescalation clinical trial using ICG to assess the safety and feasibility of NIR-guided SLN identification in patients with early-stage NSCLC via either an open thoracotomy imaging platform or a thoracoscopic NIR system.

\section{METHODS \\ Eligibility}

After informed consent, a total of 46 patients scheduled to undergo lung resection for known or suspected lung cancer were enrolled between February 2009 and February 2013 in this dose-escalation SLN trial approved by the Dana Farber Cancer Institute Institutional Review Board (Boston, Mass). Exclusion criteria included younger than 18 years, pregnancy, lactation, and allergy to iodine, shellfish, or ICG. Eight patients were subsequently ineligible as the result of subsequent data excluding stage I/II NSCLC, withdrawal of consent before surgery, or equipment repair $(\mathrm{n}=1)$. Therefore, 38 patients received an intraoperative peritumoral injection of ICG and underwent NIR-mediated SLN mapping. All study patients underwent preoperative chest CT and PET/CT scanning, with cervical mediastinoscopy or endobronchial ultrasound generally performed in patients with tumors larger than $2 \mathrm{~cm}$, mediastinal lymphadenopathy ( $>1$-cm lymph nodes), PET avid nodes, or more central tumors. In the current study, in which all patients were required to have a negative PET/CT scan result or a prior negative cervical mediastinoscopy for enrollment, 13 $(34 \%)$ of the 38 study patients also underwent additional surgical staging via mediastinoscopy or endobronchial ultrasound before this study.

\section{ICG Preparation}

ICG was purchased from Akorn, Inc (IC-GREEN, Decatur, Ill) or directly from Novadaq Technologies (Bonita Springs, Fla), resuspended in $10 \mathrm{~mL}$ sterile saline to yield a stock solution of $3.2 \mathrm{mM}$, and appropriately diluted in $50 \mathrm{~mL}$ of fresh-frozen plasma (FFP) or $25 \%$ human serum albumin (HSA; Baxter, Deerfield, Ill) to yield ICG:FFP or ICG:HSA concentrations of $10 \mu \mathrm{M}$ to $3.2 \mathrm{mM}$. FFP was used in the initial 18 patients as a coupling agent for ICG until NIR mapping in other organ systems demonstrated technical equivalence in image quality with HSA, which was used thereafter to avoid potential infectious risks with FFP exposure. ${ }^{17}$

\section{NIR Fluorescence Imaging Systems}

Real-time NIR fluorescence images were obtained using either the FLARE open surgery imaging system ${ }^{21}$ or a $10-\mathrm{mm}$ thoracoscopic NIR camera supplied by Novadaq Technologies. Each system captures both white light and NIR fluorescence images and simultaneously displays these images in real time. Video output contains 3 images of the surgical field: a white light image (ie, color video as seen by the human eye), a pure NIR image (a black-and-white image), and a merged NIR pseudocolored (green) image superimposed on the white light video image. This approach avoids obscuring the surgical field with visible contrast agents while providing the ability to correlate NIR images with surgical anatomy.

\section{Intraoperative NIR Imaging Technique in Patients With Suspected Lung Cancer}

The basic technique for intrathoracic NIR imaging has been previously described, although success with low-dose ICG has been limited. ${ }^{23}$ Based on preclinical trials in large animals and these earlier studies, ${ }^{24}$ the initial ICG dose was $3.8 \mu \mathrm{g}$ and increased to $2500 \mu \mathrm{g}$ during this dose-escalation trial. Briefly, after induction of anesthesia and surgical incision(s), ICG:FFP or ICG:HSA formulations were injected using NIR guidance into the lung parenchyma using a 25-gauge needle in 4 sites surrounding the suspected lung cancer. Before tumor excision, the lung was ventilated for 5 minutes to facilitate ICG migration within the lymphatic channels to the SLN. Visualization of lymphatic pathways and SLN in situ was attempted using NIR imaging via the open platform, when patients underwent surgical resection via a thoracotomy, or the minimally invasive NIR thoracoscope, for videoassisted thoracoscopic surgery procedures. The location of the visualized SLN was noted, and the known or suspected lung cancer was resected in the standard manner, as determined by the surgeon. If benign, no further surgery was performed and the SLN was left in situ, although the location was recorded. If the tumor was malignant, the NIR-identified SLN was resected, followed by lymphadenectomy, as determined by the surgeon, with subsequent imaging of the lymphadenectomy specimen and the surgical field to ensure that all SLNs were identified and removed. The SLN identification rate, time to identification, number of SLNs identified, SLN station, and pathology were recorded. Post-resection images of all specimens and the operative site were stored for subsequent review to confirm NIR status. SLNs were fixed in formalin and embedded in paraffin for standard hematoxylin and eosin (H\&E) analysis. If sufficient tissue was available after routine clinical analysis, in-depth analysis of the NIR-identified SLNs for micrometastatic disease was performed, which involved transverse sectioning of the paraffin-embedded SLN at $1.5-\mathrm{mm}$ intervals with $\mathrm{H} \& \mathrm{E}$ analysis of 
TABLE 1. Dose-escalation of ICG and successful intraoperative sentinel lymph node mapping in patients with NSCLC

\begin{tabular}{|c|c|c|c|c|c|c|c|}
\hline Patient no. & $\begin{array}{c}\text { Location of } \\
\text { tumor }\end{array}$ & $\begin{array}{c}\text { Tumor } \\
\text { size, } \mathbf{c m}\end{array}$ & $\begin{array}{l}\text { Type of surgical } \\
\text { resection }\end{array}$ & Tumor pathology & ICG dose, $\mu \mathrm{g}$ & SLN found? & SLN node station* \\
\hline 1 & RUL & 1.2 & Segmentectomy & Adenocarcinoma & 3.8 & No & - \\
\hline 2 & RUL & 1.0 & Wedge resection & Adenocarcinoma & 3.8 & No & - \\
\hline 3 & LUL & 1.3 & Wedge resection & Metastatic prostate cancer & 3.8 & No $\dagger$ & - \\
\hline 4 & LUL & 1.1 & Wedge resection & Adenocarcinoma & 3.8 & No & - \\
\hline 5 & RUL & 7.0 & Lobectomy & Adenocarcinoma & 7.75 & No & - \\
\hline 6 & $L U L$ & 6.0 & Lobectomy & Adenocarcinoma & 7.75 & Yes & $4 L$ \\
\hline 7 & LLL & 2.0 & Lobectomy & Adenocarcinoma & 7.75 & No & - \\
\hline 8 & RML & 3.0 & Lobectomy & Adenocarcinoma & 7.75 & No & - \\
\hline 9 & RLL & 2.2 & Lobectomy & Adenocarcinoma & 7.75 & No & - \\
\hline 10 & RLL & 3.8 & Segmentectomy & Adenocarcinoma & 15.5 & No & - \\
\hline 11 & LUL & 2.1 & Lobectomy & Adenocarcinoma & 15.5 & No & - \\
\hline 12 & L hilum & 3.7 & Pneumonectomy & Squamous cell & 100 & No & - \\
\hline 13 & RUL & 1.3 & Segmentectomy & Squamous cell & 100 & Yes & $10.1 \mathrm{R}, 10.2 \mathrm{R}, 10.3 \mathrm{R}$ \\
\hline 14 & RUL & 1.7 & Lobectomy & Large cell & 100 & Yes & 11R \\
\hline 15 & LLL & 1.5 & Segmentectomy & Metastatic melanoma & 200 & No $\dagger$ & - \\
\hline 16 & RUL & 2.3 & Lobectomy & Adenocarcinoma & 200 & Yes & 10.1R \\
\hline 17 & LUL & 2.4 & Wedge resection & Adenocarcinoma & 200 & No & - \\
\hline 18 & RLL & 3.0 & Lobectomy & Squamous cell & 400 & No & - \\
\hline 19 & RLL & 1.4 & Wedge resection & Nocardiosis & 400 & No $\dagger$ & - \\
\hline 20 & LUL & 0.9 & Lobectomy & Adenocarcinoma & 400 & No & - \\
\hline 21 & RML & 0.3 & Segmentectomy & Adenocarcinoma & 600 & No & - \\
\hline 22 & LUL & 0.6 & Wedge resection & Adenocarcinoma & 600 & No & - \\
\hline 23 & LUL & 1.6 & Segmentectomy & Adenocarcinoma & 600 & Yes & $10 \mathrm{~L}, 11 \mathrm{~L}$ \\
\hline 24 & RLL & 4.0 & Wedge resection & Adenocarcinoma & 800 & Yes & 9R \\
\hline 25 & RUL & 3.2 & Lobectomy & Adenocarcinoma & 800 & Yes & 10.1R, 11R \\
\hline 26 & RUL & 2.0 & Wedge resection & Adenocarcinoma & 800 & No & - \\
\hline 27 & RLL & 1.1 & Wedge resection & Adenocarcinoma & 800 & No & - \\
\hline 28 & RUL & - & Wedge resection & Necrotizing granuloma & 800 & No $\dagger$ & - \\
\hline 29 & RUL & 1.2 & Wedge resection & Sarcomatoid carcinoma & 1000 & Yes & $\mathbf{4 R}$ \\
\hline 30 & LUL & 2.6 & Lobectomy & Adenocarcinoma & 1000 & Yes & $9.1 \mathrm{~L}, 10.1 \mathrm{~L}$ \\
\hline 31 & RUL & 0.9 & Wedge resection & Lymphoma & 1000 & $\begin{array}{r}\text { Technical } \\
\text { failure } \ddagger\end{array}$ & - \\
\hline 32 & LUL & 6.5 & Lobectomy & Adenocarcinoma & 1000 & Yes & $5,10.1 \mathrm{~L}$ \\
\hline 33 & RML & 1.5 & Lobectomy & Adenocarcinoma & 1000 & No & - \\
\hline 34 & LLL & 1.0 & Segmentectomy & Adenocarcinoma & 1000 & Yes & $10.1 \mathrm{~L}$ \\
\hline 35 & RUL & 1.1 & Wedge resection & Adenocarcinoma & 2500 & Yes & 4.1R, 10.1R \\
\hline 36 & RML & 2.4 & Lobectomy & Adenocarcinoma & 2500 & Yes & $4 R, 10.1 R, 10.2 R$ \\
\hline 37 & LUL & 2.0 & Lobectomy & Squamous cell & 2500 & Yes & $10.1 \mathrm{~L}, 10.2 \mathrm{~L}$ \\
\hline 38 & RLL & 2.9 & Lobectomy & Adenocarcinoma & 2500 & Yes & 11.1R, 11.2R \\
\hline
\end{tabular}

Italics denote doses $<800 \mu \mathrm{g}$. Bold indicates those patients in which a sentinel lymph node was identified via NIR imaging. ICG, Indocyanine green; $N S C L C$, non-small cell lung cancer; $S L N$, sentinel lymph node; $R U L$, right upper lobe; $L U L$, left upper lobe; $L L L$, left lower lobe; $R M L$, right middle lobe; $L$, left; $R$, right. *Nodes retrieved from the same nodal station (x) are labeled in sequential order as x.1, x.2, to maintain individual identity. $\dagger$ No nodes were removed given the finding of nonlung cancer pathology. $\ddagger$ After injection, there was a camera malfunction with loss of video display prior to imaging.

superficial, middle, and deep aspects of the SLN and immunohistochemistry of the step sections for AE1/AE3 cytokeratin, cytokeratin 7, and thyroid transcription factor 1. Micrometastases were defined as tumor aggregates of 0.2 to $2 \mathrm{~mm}$ and isolated tumor cells or clusters if those aggregates measured less than $0.2 \mathrm{~mm}$.

\section{RESULTS}

\section{Patient Demographics}

A total of 25 female and 13 male patients, for a total of 38 patients with suspected stage I/II NSCLC, underwent peritumoral injection of ICG at surgical resection. The median age was $64.9 \pm 10.3$ years. There was a predominance of right and left upper lobe tumors, although tumors in all 5 anatomic lobes were represented. Lung resections included wedge, segmentectomy, lobectomy, or pneumonectomy, as determined by the attending surgeon, with most tumors removed via lobectomy or segmentectomy. Tumor location, extent of surgical resection performed, and pathology of the resected lung nodule for each patient are listed in Table 1. A total of 33 patients had NSCLC, with adenocarcinoma representing more than $80 \%$ of all tumors resected, regardless of the lobe of origin. 


\section{Dose Titration of ICG}

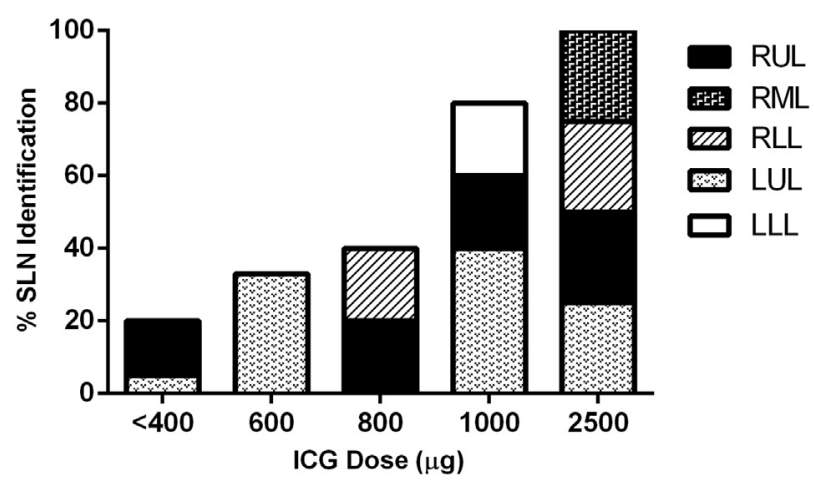

FIGURE 1. Sentinal lymph node $(S L N)$ identification. A dose-dependent increase in SLN identification is demonstrated as a function of indocyanine green (ICG) dose from 3.8 to $2500 \mu \mathrm{g}$. The SLN identification rate was $100 \%$ in the highest cohort. $R U L$, Right upper lobe; $R M L$, right middle lobe; $R L L$, right lower lobe; $L U L$, left upper lobe; $L L L$, left lower lobe.

\section{Intraoperative NIR Imaging With ICG Dose Escalation}

NIR imaging using ICG was performed in a total of 38 patients over an ICG dose range of 3.8 to $2500 \mu \mathrm{g}$. Eighteen patients underwent intraoperative NIR imaging using an open imaging system at thoracotomy, and 20 patients underwent videoscopic exploration and intraoperative NIR imaging using a minimally invasive thoracoscope. For doses of less than $600 \mu \mathrm{g}$, unreliable lymphatic migration and SLN identification were demonstrated because only $4(20 \%)$ of 20 patients demonstrated positive lymphatic tracking and SLN identification. However, in each successive cohort of $600,800,1000$, and $2500 \mu \mathrm{g}$, lymphatic migration and SLN identification improved, with the rate of SLN identification increasing from $33 \%$ to $40 \%, 80 \%$, and $100 \%$, respectively (Figure 1).

\section{NIR-Guided SLN Identification}

Of the 38 patients enrolled in the study, 5 did not have NSCLC and, thus, no SLN dissection or subsequent lymphadenectomy was performed. In the 33 patients with NSCLC and, therefore, available for lymph node analysis, a total of 26 sentinel lymph nodes were identified intraoperatively in 15 patients (Table 1). Figure 2 is an intraoperative image of lymphatic migration visualized in situ with identification of the SLN in green. Time from ICG injection to SLN identification and subsequent removal using NIR imaging ranged from 3 to 125 minutes (when resection of the primary tumor was required to establish NSCLC diagnosis before SLN removal could be performed), with a mean time of 30 minutes. All resected SLNs were imaged ex vivo to confirm NIR positivity. Figure 3 is an ex vivo image of an SLN in normal white light, pure NIR, and a merged pseudocolored (white light-NIR) image highlighting the appearance and the localization of the NIR signal within the SLN.

After NIR imaging, patients with NSCLC underwent a radical lymphadenectomy or lymph node sampling at the surgeon's discretion, and all specimens were imaged for any additional $\mathrm{NIR}^{+} \mathrm{SLN}$, of which none was identified in this study. The average number of lymph node stations sampled per patient within the resected surgical specimen was $2.9 \pm 2$ (ie, hilar, levels 4 and 7), and they were independent from prior stations sampled via mediastinoscopy, endobronchial ultrasound, or SLN mapping. In addition, the average number of additional nodes harvested per patient was a minimum of $6.5 \pm 5.3$, because multiple nodes from the same station were often not counted separately on the final pathology report.

The location of the 26 identified $\mathrm{NIR}^{+}$SLNs in relation to the primary tumor and injection site is illustrated in Figure 4. Nineteen of these lymph nodes were identified in the hilar $(\mathrm{n}=14)$ or interlobar $(\mathrm{n}=5) \mathrm{N} 1$ stations. Of the 7 lymph nodes in the $\mathrm{N} 2$ stations, 2 were identified in the pulmonary ligament (station 9), 1 in the aortopulmonary window (station 5), and 4 in the superior mediastinum (station 4). SLNs from the left upper lobe seemed to be particularly diverse in their location.

\section{Histologic Analysis of NIR ${ }^{+}$SLNs}

Of the 26 nodes identified with NIR guidance in 15 patients, 7 SLNs (6 patients) demonstrated evidence of
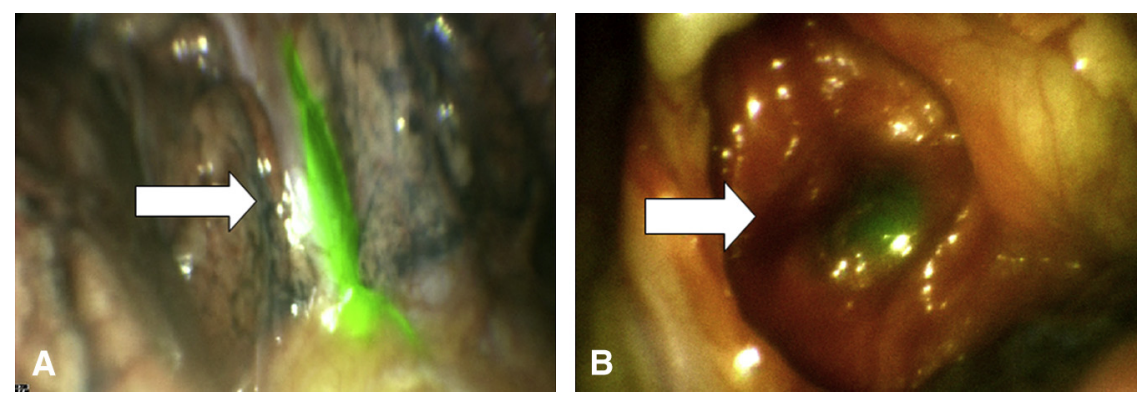

FIGURE 2. Intraoperative real-time identification of sentinel lymph nodes (SLNs) using near-infrared (NIR) fluorescent imaging. A, The lymphatic migration of indocyanine green is noted in green and progresses from the site of injection toward the hilum (arrow). B, The SLN is identified using NIR fluorescent imaging and is shown in green (arrow). 

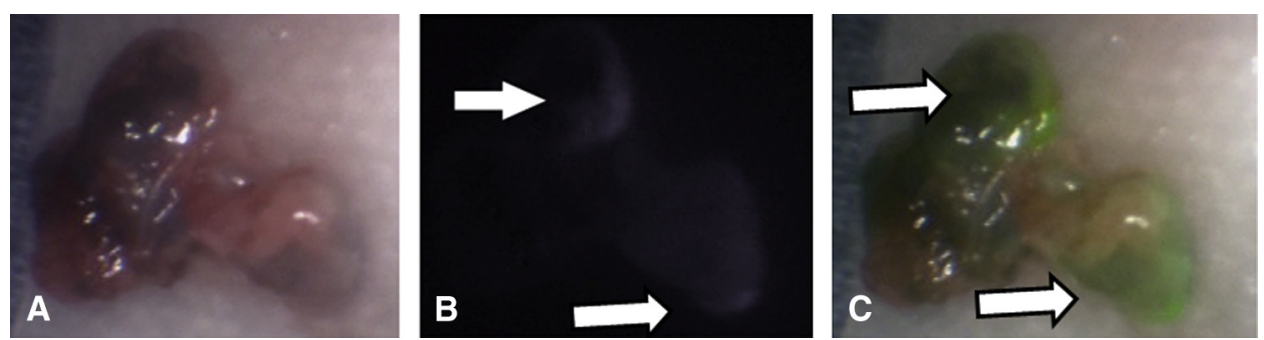

FIGURE 3. Ex vivo sentinel lymph node (SLN) imaging using near-infrared (NIR) fluorescent imaging. After intraoperative identification and excision of the SLN, the SLN is imaged ex vivo using NIR imaging to confirm fluorescence. A, White light image of the SLN. B, Pure NIR image demonstrating NIR fluorescence in white (arrowhead). C, Merged pseudocolored image of the SLN with NIR fluorescence within the SLN shown in green.

previously unknown metastatic disease on subsequent $\mathrm{H} \& \mathrm{E}$ analysis (Table 2). All 7 histologically positive $\mathrm{NIR}^{+}$SLNs were located within level 10 or 11 nodal stations. Although metastatic disease was identified in some patients in additional lymph nodes within the surgical lymphadenectomy specimen, it is significant that these nodes were generally at the same or more proximal lymph node stations, thus signifying lymphatic spread of metastatic disease beyond the SLN. Metastatic nodal disease was never identified in patients with a histologically negative $\mathrm{NIR}^{+}$SLN. In fact, in 2 of the 6 patients, the only histologically positive node, including those within the surgical lymphadenectomy

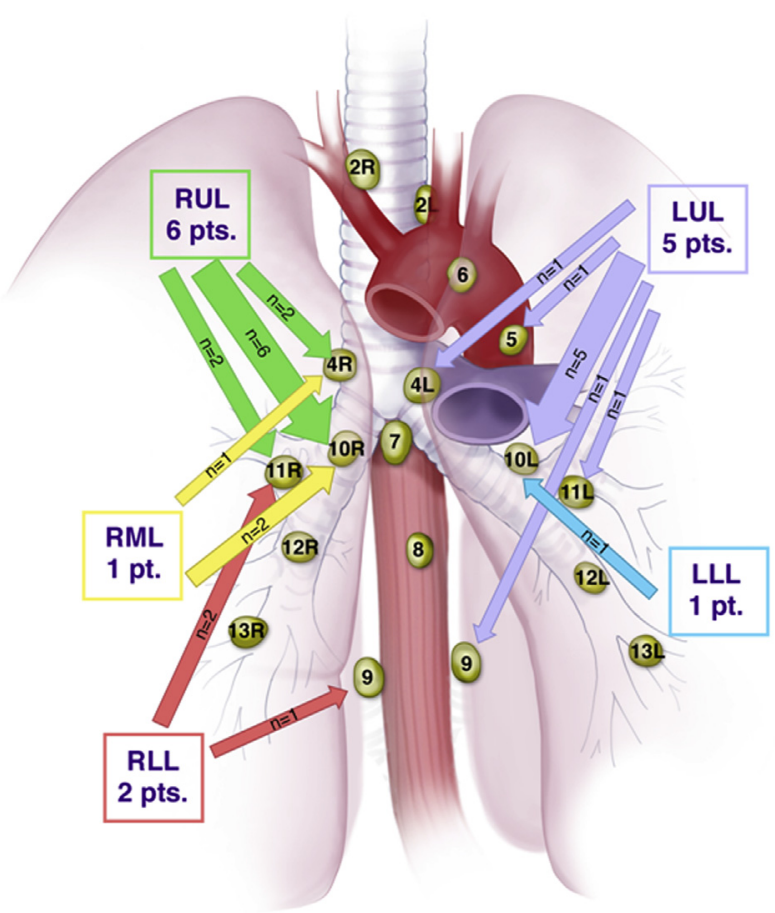

FIGURE 4. Lymphatic map of sentinel lymph node (SLN) stations identified via near-infrared (NIR) image guidance: a total of $26 \mathrm{NIR}^{+}$SLNs were identified in 15 patients. The location of the identified SLNs in relation to the site of the primary tumor (and injection site) is demonstrated. $R U L$, Right upper lobe; $L U L$, left upper lobe; $R M L$, right middle lobe; $L L L$, left lower lobe; $R L L$, right lower lobe; $L$, left; $R$, right. specimen, was the single SLN identified via NIR imaging. Interestingly, in-depth immunohistochemical analysis on $7 \mathrm{NIR}^{+}$SLNs deemed negative by standard H\&E did not reveal evidence of occult metastatic disease.

\section{DISCUSSION}

Sentinel lymph node biopsy is a well-established prognostic indicator and important criterion in the staging of malignant disease for many cancers. However, standard approaches with blue dye and radioisotopes have not translated into successful identification of the $\mathrm{SLN}(\mathrm{s})$ in patients with NSCLC. Little and colleagues ${ }^{11}$ first attempted SLN biopsy in lung cancer in 1999 , with only a $47 \%$ success rate. In 2000, Liptay and colleagues ${ }^{12,13}$ successfully used technetium for SLN identification in $87 \%$ of patients with lung cancer; however, these results were not reproducible in a phase 2 multicenter Cancer and Leukemia Group B (CALGB) trial that noted SLN identification in only $51 \%$ of patients. Variations of techniques have been attempted, but results have been unreliable, with poor sensitivity and/ or specificity. ${ }^{11-16}$ Suboptimal results have been attributed to anthractic nodes in the thorax, a "shine-through" effect (in which a high radioactive signal from the injection site produces false-positive results because of increased background signal in nearby tissues), and distortion of critical anatomy by blue dye.

NIR imaging has specific advantages over current SLN mapping techniques and has proved effective in multiple cancers, including breast, cervical, gastrointestinal, and skin cancers. ${ }^{17-20}$ The current study confirms that NIR imaging can be performed intraoperatively, in real time during lung surgery, for visualization of lymph nodes without distortion of critical intrathoracic structures, as seen with blue dyes or the radioactive risk associated with radioisotopes. Although only a single institutional proofof-concept study, at least 1 SLN was identified in all patients within the 2500- $\mu \mathrm{g}$ ICG dose cohort. Although this early dose-escalation trial is not able to determine the role of NIR imaging in the staging of patients with NSCLC, we have identified a dose-response for SLN identification and demonstrated safety and feasibility of minimally 
TABLE 2. SLN vs non-SLN pathology for all patients with NIR ${ }^{+}$SLNs

\begin{tabular}{|c|c|c|c|c|c|c|c|c|c|c|}
\hline \multirow[b]{2}{*}{$\begin{array}{c}\text { Patient } \\
\text { no. }\end{array}$} & \multirow[b]{2}{*}{$\begin{array}{l}\text { Tumor } \\
\text { location }\end{array}$} & \multirow[b]{2}{*}{$\begin{array}{l}\text { Tumor } \\
\text { size, } \mathbf{c m}\end{array}$} & \multirow[b]{2}{*}{ Tumor pathology } & \multirow[b]{2}{*}{$\begin{array}{l}\text { SLN node } \\
\text { station* }\end{array}$} & \multirow[b]{2}{*}{ SLN pathology } & \multirow[b]{2}{*}{$\mathbf{I H C} \dagger$} & \multirow{2}{*}{$\begin{array}{l}\text { No. of node } \\
\text { stations } \\
\text { sampled } \ddagger\end{array}$} & \multirow[b]{2}{*}{$\begin{array}{c}\text { No. of nodes } \\
\text { harvested } \S\end{array}$} & \multicolumn{2}{|c|}{ Non-SLN pathology } \\
\hline & & & & & & & & & Positive & Negative \\
\hline 6 & LUL & 6.0 & Adenocarcinoma & $4 \mathrm{~L}$ & Negative & Negative & 4 & 9 & None & $5,10 \mathrm{Ls}, 11 \mathrm{~L}$ \\
\hline 13 & RUL & 1.3 & Squamous cell & $\begin{array}{l}10.1 \mathrm{R} \\
10.2 \mathrm{R} \\
10.3 \mathrm{R}\end{array}$ & Negative & Negative & 2 & 6 & None & $\begin{array}{c}10 \mathrm{R} \times 2, \\
\text { Intraparenchymal } \\
\text { LNs }\end{array}$ \\
\hline 14 & RUL & 1.7 & Large cell & $11 \mathrm{R}$ & Negative & Negative & 2 & 3 & None & $4 \mathrm{R} \times 2$ \\
\hline 16 & RUL & 2.3 & Adenocarcinoma & $10.1 \mathrm{R}$ & Negative & Negative & 1 & 3 & None & $10 \mathrm{R} \times 2$ \\
\hline 23 & LUL & 1.6 & Adenocarcinoma & $\begin{array}{l}10 \mathrm{~L} \\
11 \mathrm{~L}\end{array}$ & Negative & Negative & 2 & 7 & None & $10 \mathrm{~L} \times 2,11 \mathrm{~L} \times 3$ \\
\hline 24 & RLL & 4.0 & Adenocarcinoma & $9 \mathrm{R}$ & Negative & Negative & 5 & 12 & None & $\begin{array}{c}7,8,9 \times 2,10 \mathrm{R} \times 5, \\
11 \mathrm{R} \times 2\end{array}$ \\
\hline 25 & RUL & 3.2 & Adenocarcinoma & $\begin{array}{c}10.1 \mathrm{R} \\
11 \mathrm{R}\end{array}$ & Negative & Negative & 3 & 6 & None & $4 \mathrm{R}, 10 \mathrm{R} \times 3$ \\
\hline 29 & RUL & 1.2 & $\begin{array}{c}\text { Sarcomatoid } \\
\text { carcinoma }\end{array}$ & $4 \mathrm{R}$ & Negative & $\begin{array}{l}\text { Insufficient } \\
\text { tissue }\end{array}$ & 1 & 2 & None & $4 \mathrm{R} \times 2$ \\
\hline 30 & LUL & 2.6 & Adenocarcinoma & $\begin{array}{r}9.1 \mathrm{~L} \\
10.1 \mathrm{~L}\end{array}$ & 10.1L Positive & & 5 & 14 & $\begin{array}{c}10 \mathrm{~L} \text { and } \\
11 \mathrm{~L} \times 3\end{array}$ & $5 \times 3,7,9 \mathrm{~L} \times 3,11 \mathrm{~L}$ \\
\hline 32 & LUL & 6.5 & Adenocarcinoma & $\begin{array}{c}5 \\
10.1 \mathrm{~L}\end{array}$ & 10.1L Positive & & 4 & 20 & $\begin{array}{c}2 \text { of } 13 \text { Hilar } \\
\text { nodes }\end{array}$ & $\begin{array}{r}4 \mathrm{~L} \times 3,10 \mathrm{~L} \times 2,11 \\
\text { of } 13 \text { hilar nodes }\end{array}$ \\
\hline 34 & LLL & 1.0 & Adenocarcinoma & $10.1 \mathrm{~L}$ & 10.1L Positive & & 1 & 2 & None & $10 \mathrm{~L}$ \\
\hline 35 & RUL & 1.1 & Adenocarcinoma & $\begin{array}{c}4.1 \mathrm{R} \\
10.1 \mathrm{R}\end{array}$ & Negative & $\begin{array}{l}\text { Insufficient } \\
\text { tissue }\end{array}$ & 2 & 5 & None & $4 \mathrm{R}, 10 \mathrm{R}$ \\
\hline 36 & RML & 2.4 & Adenocarcinoma & $\begin{array}{c}4 \mathrm{R} \\
10.1 \mathrm{R} \\
10.2 \mathrm{R}\end{array}$ & $\begin{array}{c}\text { 10.1R and } \\
\text { 10.2R } \\
\text { Positive }\end{array}$ & & 3 & 6 & $\begin{array}{c}7 \\
10 R\end{array}$ & $10 \mathrm{R}$ \\
\hline 37 & LUL & 2.0 & Squamous cell & $\begin{array}{l}10.1 \mathrm{~L} \\
10.2 \mathrm{~L}\end{array}$ & 10.1L Positive & & 4 & 8 & $\begin{array}{l}5 \times 2 \text { and } \\
710 \mathrm{~L}, 11 \mathrm{~L}\end{array}$ & $11 \mathrm{~L}$ \\
\hline 38 & RLL & 2.9 & Adenocarcinoma & $\begin{array}{l}11.1 \mathrm{R} \\
11.2 \mathrm{R}\end{array}$ & 11.2R Positive & & 6 & 14 & None & $\begin{array}{c}4 \mathrm{R} \times 2,7 \times 2,8,9 \\
10 \mathrm{R} \times 5,11 \mathrm{R}\end{array}$ \\
\hline
\end{tabular}

Bold denotes positive lymph node pathology and indicates that these nodes showed metastatic disease within the respective highlighted lymph node. $S L N$, Sentinel lymph node; $N I R$, near infrared; $I H C$, immunohistochemistry; $L U L$, left upper lobe; $L$, left; $R U L$, right upper lobe; $R$, right; $L N$, lymph node; $R M L$, right middle lobe. *Nodes retrieved from the same nodal station are labeled in sequential order as *.1, *.2, etc, to maintain individual specimen identity, with multiple nodes shown as $\times 2$ or $\times 3$, etc. $\dagger$ IHC only available if sufficient tissue available after all clinically necessary analysis performed for patient care. $\Varangle$ Node stations sampled in addition to stations sampled via cervical mediastinoscopy, endobronchial ultrasound, and SLN mapping. §Minimum number of nodes harvested because multiple nodes within a given station often grouped together.

invasive NIR-guided SLN mapping in patients with earlystage NSCLC. Furthermore, although the primary objective of this trial was to establish safety and dose-response, we have shown that SLN identification can lead to detection of nodal metastatic disease and permit increased histologic analysis via immunohistochemistry or other modalities, with the goal of improving NSCLC staging.

Although the ICG dose required for intrathoracic SLN visualization is higher than that required for clinical SLN imaging in patients with breast cancer and melanoma, this study reports success at significantly lower doses than used for cardiac output measurements or other lung imaging. ${ }^{17,20,25}$ Surprisingly, despite sequential doubling of the successful ICG dose used for lung SLN mapping in swine (ie, $10 \mu \mathrm{g}$ ), SLNs were not identified in humans at these low doses. Similar findings in translation of NIR technology to human patients with breast cancer resulted in a new dose-escalation scheme starting at $100 \mu \mathrm{g}$, suggesting that, despite the similar size of humans and large-animal models, lymphatic mapping may fundamentally differ between species and organ systems. Since commencement of our trial in 2009, our dose of ICG has increased significantly from 3.8 to $2500 \mu \mathrm{g}$. The current dose of $2500 \mu \mathrm{g}$ is higher than the $488 \mu \mathrm{g}$ used in NIR imaging for patients with both melanoma and breast cancer ${ }^{17,20}$ but far less than the 5- to 10-mg doses previously reported in Japanese studies. ${ }^{25}$ Given the reported risk, albeit rare, of anaphylaxis and distortion of visual anatomy using high doses of ICG, our goals were to identify a safe, optimal dose for injection that did not alter surgical vision, yet resulted in identification of lymphatic migration in patients with lung cancer. We have demonstrated the dose-dependent identification of SLN, with success at doses of 1000 to $2500 \mu \mathrm{g}$. Although the sample size is small, the detection of SLN in all patients within the 2500- $\mu \mathrm{g}$ cohort suggests that, although metastatic disease can reach the contralateral lymph node basins, localization of the first draining lymph node (ie, SLN) to these contralateral nodes is likely rare. Given the absence 
of $\mathrm{NIR}^{+}$nodes within the surgical lymphadenectomy specimen at any dose, failure to identify the SLN in $20 \%$ of patients at a dose of $1000 \mu \mathrm{g}$ is unlikely to be the result of SLNs being present elsewhere in the mediastinum, but certainly could be the result of inadequate ICG dose or secondary to ICG leakage from the intraparenchymal injection site. We are working on methods to improve our technique to maximize SLN detection.

Although lymphatic mapping may be affected by the bulk of metastatic nodal disease, the patients in this study were specifically chosen to clinically have no evidence of nodal disease, as evident by negative PET/CT and/or cervical mediastinoscopy results. ${ }^{26}$ Nonetheless, tumors of various sizes and lobar locations were included in both high- and low-dose ICG cohorts, given that tumor size has correlated with the incidence of metastatic nodal disease. Similar to previously published data for SLN biopsy specimens in patients with breast cancer, ${ }^{27,28}$ the results of the current study did not demonstrate a relationship between positive identification of SLNs and tumor size or location. Instead, ICG dose was the primary factor determining the likelihood of SLN identification in this study. However, it was evident that there is significant variability in the lymphatic drainage patterns from the lung tumor to SLN. Although nearly three-quarters of the $26 \mathrm{NIR}^{+}$SLNs identified were located in the nearby N1 stations, a surprising $27 \%$ of patients had SLN that had "skipped" to an N2 station, placing them at risk for having occult stage III disease despite a preoperative assessment of clinical stage I disease. This is consistent with the $20 \%$ to $30 \%$ incidence of skip metastases reported by others using technetium 99 and demonstrates the importance of accurately identifying the SLN in these patients. ${ }^{29,30}$

Only 3 SLN nodes were identified in the intralobar position (station 11), with no SLN identified in the more distal sublobar and segmental positions. We hypothesize that this is the result of high fluorescence at the injection site and surrounding lung parenchyma, which can obscure our ability to identify a discrete separate NIR signal higher than background within the intraparenchymal lymph node stations (segmental and subsegmental), causing the equivalent of a "shine effect." We have decreased the impact of this by positioning the injection site out of the visual field while looking at the hilum and mediastinum, but this may still be affecting our ability to image nodes closer to the tumor itself. Second, imaging is particularly difficult if ICG leaks from the injection site onto the nearby lung, which may have distorted our ability to identify discrete nodes in these lymph node stations and suggests that individual imaging of segmental nodes dissected ex vivo from the resected specimen may have identified additional SLN nodes in these stations. Third, although NIR imaging is feasible for up to $1 \mathrm{~cm}$ in depth, ${ }^{22}$ this does not appear to be the case in air-filled lung or within the mediastinum around the bronchial structures. Having said this, final pathology has not identified metastatic nodes within the more distal segmental positions, even in those patients with metastatic SLN identified in the level 10 or 11 nodes, indicating that the identified $\mathrm{NIR}^{+}$SLNs are sufficient for identification of metastatic nodal disease.

The high incidence of mediastinal (N2) SLN and the variability of SLN location between patients highlight the difficulty in predicting the site of metastatic nodal disease in patients with NSCLC. In the current trial, despite a negative preoperative workup via PET and possible mediastinoscopy, 7 lymph nodes were positive for metastatic disease on H\&E staining. Therefore, although our numbers are small, SLN analysis resulted in the upstaging of 6 of the 15 patients with NSCLC in whom SLNs were identified in this study. This suggests that $40 \%$ of patients were understaged preoperatively, which is not significantly different than the $27.5 \%$ of patients with stage I NSCLC who had node-positive disease at resection, despite a negative preoperative workup, in CALGB $9761 .^{31}$

Identification of the sentinel lymph node in patients with NSCLC may allow for detailed histologic analysis via immunohistochemistry or polymerase chain reaction, thereby leading to more accurate staging in NSCLC. Although immunohistochemical assessment of a few SLNs found to be negative on H\&E in this study has not yet identified occult metastases, we expect that additional analysis, including polymerase chain reaction, in a larger population will potentially identify micrometastatic disease in a subset of these H\&E-negative SLNs. This may result in identification of patients who may benefit from adjuvant therapy for previously undetected occult disease, with the goal of improving survival. Our current phase 1 trial has identified an ICG dose-response for SLN identification and has demonstrated the safety and feasibility of NIR imaging for SLN identification in patients undergoing resection for NSCLC via a minimally invasive, intraoperative approach. Although we have demonstrated the detection of metastatic disease within $\mathrm{NIR}^{+}$SLNs, additional studies are needed to improve SLN imaging and dose delivery, determine sensitivity and specificity of this approach, and ultimately assess the impact of SLN analysis on adjuvant therapy and overall outcomes in patients with early-stage NSCLC.

\section{References}

1. Billé A, Pelosi E, Skanjeti A, Arena V, Errico L, Borasio P, et al. Preoperative intrathoracic lymph node staging in patients with non-small-cell lung cancer: accuracy of integrated positron emission tomography and computed tomography. Eur J Cardiothorac Surg. 2009;36:440-5.

2. Tsang GM, Watson DC. The practice of cardiothoracic surgeons in the perioperative staging of non-small cell lung cancer. Thorax. 1992;47:3-5.

3. Little AG, Rusch VW, Bonner JA, Gaspar LE, Green MR, Webb WR, et al. Patterns of surgical care of lung cancer patients. Ann Thorac Surg. 2005;80:2051-6.

4. Verhagena AF, Schoenmakersa MC, Barendregtb W, Smitc H, van Bovend WJ, Looijene M, et al. Completeness of lung cancer surgery: is mediastinal dissection common practice? Eur J Cardiothorac Surg. 2012;41:834-8. 
5. Mountain CF. Revisions in the International System for Staging Lung Cancer. Chest. 1997;111:1710-7.

6. Takizawa T, Terashima M, Koike T, Watanabe T, Kurita Y, Yokoyama A, et al. Lymph node metastasis in small peripheral adenocarcinoma of the lung. Thorac Cardiovasc Surg. 1998;116:276-80.

7. Kubuschok B, Passlick B, Izbicki JR, Thetter O, Pantel K. Disseminated tumor cells in lymph nodes as a determinant for survival in surgically resected nonsmall cell lung cancer. J Clin Oncol. 1999;17:19-24.

8. Howlader N, Noone AM, Krapcho M, Neyman N, Aminou R, Waldron W, et al. Seer Cancer Statistic Review, 1975-2008. Bethesda, MD: National Cancer Institute; 2010.

9. Morton DL, Wen DR, Wong JH, Economou JS, Cagle LA, Storm FK, et al. Technical details of intraoperative lymphatic mapping for early stage melanoma. Arch Surg. 1992;127:392-9.

10. Giuliano AE, Kirgan DM, Guenther JM, Morton DL. Lymphatic mapping and sentinel lymphadenectomy for breast cancer. Ann Surg. 1994;220:391-8.

11. Little A, DeHoyos A, Kirgan DM, Arcomano TR, Murray KD. Intraoperative lymphatic mapping for non-small cell lung cancer: the sentinel node technique. J Thorac Cardiovasc Surg. 1999;117:220-4

12. Liptay MJ, Master GA, Winchester DJ, Edelman BL, Garrido BJ, Hirschtritt TR, et al. Intraoperative radioisotope sentinel lymph node mapping in non-small cell lung cancer. Ann Thorac Surg. 2000;70:384-9.

13. Liptay MJ, D’Amico TA, Nwogu C, Demmy TL, Wang XF, Gu L, et al. Intraoperative sentinel node mapping with technitium-99 in lung cancer: results of CALGB 140203 multicenter phase II trial. J Thorac Oncol. 2009;4:198-202.

14. Noromi H. Sentinel lymph node mapping in lung cancer: the Japanese experience. Semin Thorac Cardiovasc Surg. 2009;21:316-22.

15. Schmidt FE, Woltering EA, Webb WR, Garcia OM, Cohen JE, Rozans MH. Sentinel nodal assessment in patients with carcinoma of the lung. Ann Thorac Surg. 2002;74:870-4; discussion 874-5.

16. Tiffet O, Nicholson AG, Khaddage A, Prevot N, Ladas G, Dubois F, et al. Feasibility of the detection of the sentinel lymph node in peripheral non-small cell lung cancer with radio isotopic and blue dye techniques. Chest. 2005;127: 443-8.

17. Mieog JS, Troyan SL, Hutteman M, Donohoe KJ, van der Vorst JR, Stockdale A, et al. Towards optimization of imaging system and lymphatic tracer for nearinfrared fluorescent sentinel lymph node mapping in breast cancer. Ann Surg Oncol. 2011;18:2483-91.

18. Crane LM, Themelis G, Pleijhuis RG, Harlaar NJ, Sarantopoulos A, Arts HJ, et al. Intraoperative multispectral fluorescence imaging for the detection of the sentinel lymph node in cervical cancer: a novel concept. Mol Imaging Biol. 2011;13:1043-9.

19. Schaafsma BE, Mieog JSD, Hutteman M, van der Vorst JR, Kuppen PJ, Löwik CW, et al. The clinical use of indocyanine green as a near-infrared fluorescent contrast agent for image-guided oncologic surgery. J Surg Oncol. 2011;104: 323-32.

20. Gilmore DM, Khullar OV, Gioux S, Stockdale A, Frangioni JV, Colson YL, et al. Effective low-dose escalation of indocyanine green for near-infrared fluorescent sentinel lymph node mapping in melanoma [published online ahead of print February 26, 2013]. Ann Surg Oncol. doi: 10.1245/s10434-013-2905-x.

21. Khullar O, Frangioni JV, Grinstaff MW, Colson YL. Image-guided sentinel lymph node mapping and nanotechnology-based nodal treatment in lung cancer using invisible near-infrared fluorescent light. Semin Thorac Cardiovasc Surg. 2010;21:309-15.

22. Tanaka E, Choi HS, Fujii H, Bawendi MG, Frangioni JV. Image-guided oncologic surgery using invisible light: completed pre-clinical development for sentinel lymph node mapping. Ann Surg Oncol. 2006;13:1671-81.

23. Gilmore DM, Khullar OV, Colson YC. Developing intrathoracic sentinel lymph node mapping with near-infrared fluorescent imaging in non small cell lung cancer. J Thorac Cardiovasc Surg. 2012;144:S80-4.

24. Khullar OV, Gilmore DM, Matsui A, Ashitate Y, Colson YL. Preclinical study of near-infrared-guided sentinel lymph node mapping of the porcine lung. Ann Thorac Surg. 2013;95:312-8.

25. Yamashita S, Tokuishi K, Miyawaki M, Anami K, Moroga T, Takeno S, et al. Sentinel node navigation surgery by thoracoscopic fluorescence imaging system and molecular examination in non-small cell lung cancer. Ann Surg Oncol. 2012; 19:728-33.

26. Lyman GH, Giuliano AE, Somerfield MR, Renson AB, Bodurka DC, Burstein HJ, et al. American Society of Clinical Oncology guideline recommendations for sentinel lymph node biopsy in early-stage breast cancer. J Clin Oncol. 2005;23:7703-20.
27. Wong SL, Chao C, Edwards MJ, Carlson DJ, Laidley A, Noyes RD, et al., University of Louisville Breast Cancer Study Group. Accuracy of sentinel lymph node biopsy for patients with T2 and T3 breast cancer. Ann Surg. 2001;67:522-6.

28. Ahrendt GM, Laud P, Tjoe J, Eastwood D, Walker AP, Otterson MF, et al. Does breast tumor location influence success of SLN biopsy. J Am Coll Surg. 2002; 194:278-84.

29. Liptay M. Sentinel node mapping in lung cancer. Ann Surg Oncol. 2004;11: 271S-4S.

30. Asamura H, Nakayama H, Kondo H, Tsuchiya R, Naruke T. Lobe-specific extent of systematic lymph node dissection for non-small cell lung carcinomas according to a retrospective study of metastasis and prognosis. J Thorac Cardiovasc Surg. 1999;117:1102-11.

31. D'Cunha J, Herndon JE 2nd, Herzan DL, Patterson GA, Kohman LJ, Harpole DH, et al. Poor correspondence between clinical and pathologic staging in stage 1 non-small cell lung cancer: results from CALGB 9761, a prospective trial. Lung Cancer. 2005;48:241-6.

\section{Discussion}

Dr Chumy Nwogu (Buffalo, NY). I enjoyed your presentation much. I have a few questions. What was your incidence of spillage of the ICG during the injection and what was the average migration time that you encountered?

Dr Gilmore. The spillage was a problem early on. One of the other Japanese groups that has done this actually uses an Endoclip following injection. We have converted to a deeper injection of about $1 \mathrm{~cm}$ of ICG in the later cohorts. While we do not have the exact statistics, we have reduced the leakage rate.

As for the migration itself, we can clearly see on the video that we see immediate identification of our injection site. We have modified our technique so that now we do perform ventilation for 1 to 2 minutes to increase the lymphatic flow and then following deflation of the lung again we can see the migration.

Dr Nwogu. What do you think prevented migration in the cases where you were unsuccessful?

Dr Gilmore. In unsuccessful cases early on, we feel that the dose was too low at that point; this was based on preclinical trials. Since we have now gone to higher doses, we feel we have more consistent and reliable imaging, and, again, in the higher doses this may be due to spillage.

Dr Nwogu. I wonder whether the ICG stops at the first echelon of the sentinel node or does it go beyond that? What was the average number of lymph nodes you identified per patient?

Dr Gilmore. The average was one lymph node identified per patient. There was only a total of 13 lymph nodes in 11 patients. There were instances where there were 2 lymph nodes identified. We do use ICG coupled with albumin, and we have seen this increases retention within the first lymph node but does not permit further migration.

Dr David Sugarbaker (Boston, Mass). I enjoyed your presentation much, and I think this has a lot of potential. I have 2 questions. Number one, what is the interoperative time required from initial injection to the identification of the sentinel node?

Dr Gilmore. It does not add a considerable amount of time to the procedure itself. We do perform the injection and then ventilate for 1 to 2 minutes to allow for increased migration. Following deflation of the lung, we are then able to identify the lymph node readily. And I think in total it may add an additional 10 to 15 minutes to the procedure. 
Dr Sugarbaker. Actually I have 2 more questions real briefly. Of interest, does the lung need to be inflated for optimal lymphatic flow? You mentioned that. Is that a prerequisite or can you do it with the lung atelectatic?

Dr Gilmore. We feel that ventilation of the lung does increase lymphatic migration. In our earlier patients, we did use a deflated lung, and we did not see as great a migration, and we feel that this may be secondary to decreased lymphatic flow.

Dr Sugarbaker. And the third thing is one of the things that concerns all of us in mapping our understanding an individual patient the lymphatic flow is crossover, particularly from lower lobes to the contralateral $4 \mathrm{R}$, so right lower lobe to $4 \mathrm{R}$ or right lower lobe to $4 \mathrm{~L}$ or left lower lobe to $4 \mathrm{R}$ as the first station. Do you see in the future the ability to map both N2 and N3 stations utilizing this technique?

Dr Gilmore. That is a good question. Currently, we do not have that possibility, because during a normal video-assisted thoracoscopic surgery resection, we do not see the contralateral side, but that is something we should consider.

Dr Sugarbaker. Thank you. 